\title{
Locating hydrothermal fluid injection of the 2018 phreatic eruption at Kusatsu-Shirane volcano with volcanic tremor amplitude
}

\author{
Taishi Yamada ${ }^{1,2^{*}} \mathbb{0}$, Aika K. Kurokawa ${ }^{2}$, Akihiko Terada ${ }^{3}$, Wataru Kanda ${ }^{3}$, Hideki Ueda², Hiroshi Aoyama ${ }^{4}$, \\ Takahiro Ohkura ${ }^{5}$, Yasuo Ogawa ${ }^{3}$ and Toshikazu Tanada ${ }^{2}$
}

\begin{abstract}
Kusatsu-Shirane volcano hosts numerous thermal springs, fumaroles, and the crater lake of Yugama. Hence, it has been a particular study field for hydrothermal systems and phreatic eruptions. On 23 January 2018, a phreatic eruption occurred at the Motoshirane cone of Kusatsu-Shirane, where no considerable volcanic activity had been reported in observational and historical records. To understand the eruption process of this unique event, we analyzed seismic, tilt, and infrasound records. The onset of surface activity accompanied by infrasound signal was preceded by volcanic tremor and inflation of the volcano for $\sim 2 \mathrm{~min}$. Tremor signals with a frequency band of $5-20 \mathrm{~Hz}$ remarkably coincide with the rapid inflation. We apply an amplitude source location method to seismic signals in the $5-20 \mathrm{~Hz}$ band to estimate tremor source locations. Our analysis locates tremor sources at $1 \mathrm{~km}$ north of Motoshirane and at a depth of 0.5-1 km from the surface. Inferred source locations correspond to a conductive layer of impermeable cap-rock estimated by magnetotelluric investigations. An upper portion of the seismogenic region suggests hydrothermal activity hosted beneath the cap-rock. Examined seismic signals in the $5-20 \mathrm{~Hz}$ band are typically excited by volcano-tectonic events with faulting mechanism. Based on the above characteristics and background, we interpret that excitation of examined volcanic tremor reflects small shear fractures induced by sudden hydrothermal fluid injection to the cap-rock layer. The horizontal distance of $1 \mathrm{~km}$ between inferred tremor sources and Motoshirane implies lateral migration of the hydrothermal fluid, although direct evidence is not available. Kusatsu-Shirane has exhibited unrest at the Yugama lake since 2014. However, the inferred tremor source locations do not overlap active seismicity beneath Yugama. Therefore, our result suggests that the 2018 eruption was triggered by hydrothermal fluid injection through a different pathway from that has driven unrest activities at Yugama.
\end{abstract}

Keywords: Kusatsu-shirane, Phreatic eruptions, Volcanic tremor, Hydrothermal system

\section{Introduction}

Kusatsu-Shirane volcano consists of three pyroclastic cones (Shirane, Ainomine, and Motoshirane), central Japan (Fig. 1). A distinguishing characteristic of KusatsuShirane is a well-developed hydrothermal system beneath

\footnotetext{
*Correspondence: yamada.taishi.8m@kyoto-u.ac.jp

${ }^{1}$ Disaster Prevention Research Institute, Sakurajima Volcano

Research Center, Kyoto University, 1722-19 Sakurajima-Yokoyama, Kagoshima 891-1419, Japan

Full list of author information is available at the end of the article
}

the volcano, evidenced by a significant amount of thermal springs, fumaroles, and a crater lake (Yugama) at the summit of the Shirane cone. Therefore, it has been a particular study field of volcano hydrothermal system and phreatic eruptions (e.g., Ossaka et al. 1980; Ohba et al. 1994; Terada and Hashimoto, 2017; Terada 2018). On 23 January 2018, a phreatic eruption occurred at KusatsuShirane and formed several small craters with diameters of $15-20 \mathrm{~m}$ at the summit area of the Motoshirane cone (Earthquake Research Institute, 2018). The 2018 eruption occurred at Motoshirane, while all documented (after 

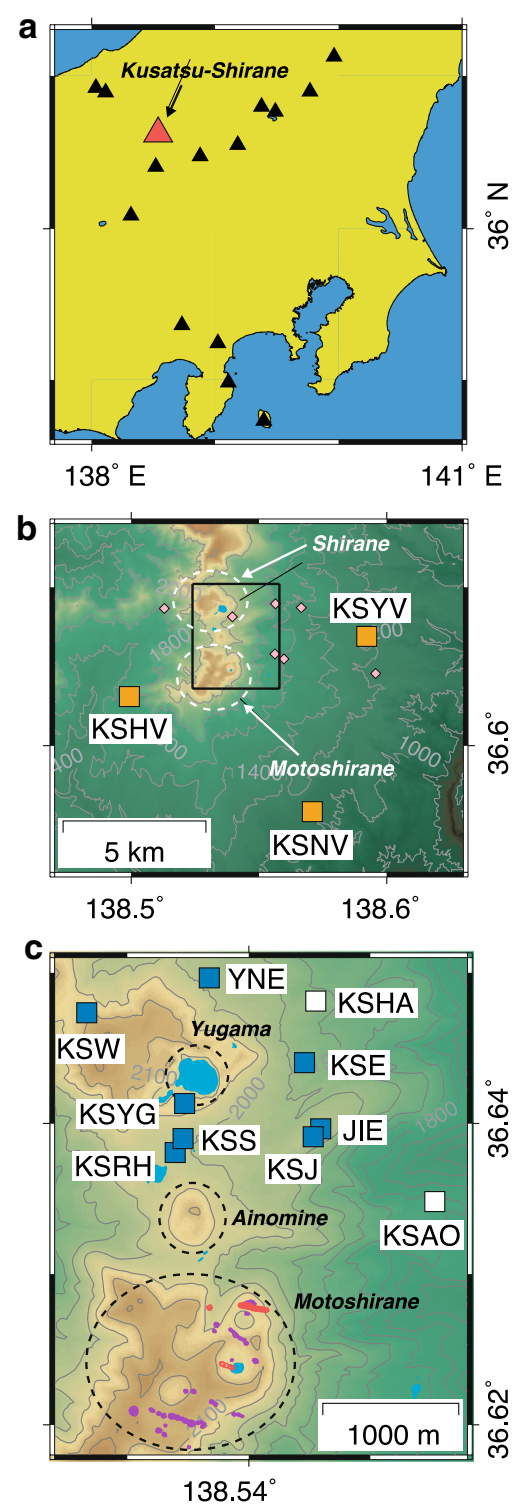

Fig. 1 a Location of Kusatsu-Shirane volcano. Black triangles denote active volcanoes defined by JMA. $\mathbf{b}$ Locations of V-net stations at Kusatsu-Shirane. Pink diamonds correspond to major thermal spring sites. A black square is the map area of $\mathbf{c}$. $\mathbf{c}$ A detailed map including Yugama, Ainomine, and Motoshirane. Blue and white squares show observation stations operated by KSVO and JMA. Vent locations of the 2018 eruption and unidentified past events are denoted by red and violet colors (GSI, 2018). Seismic data at YNE and KSJ are adopted in hypocenter determinations by KSVO, although we do not adopt these into the ASL analysis in this paper

1882) phreatic eruptions have occurred at the Shirane cone, including recent unrest events in 1989-1991 and 2014 (Terada 2018). No considerable precursory changes related to Motoshirane have been reported before the event. Phreatic eruptions are not always accompanied by clear precursors (Barberi et al. 1992). Assessing the potential of upcoming phreatic eruptions is an important challenge for volcano research and monitoring. Hence, case studies for each event are still valuable to improve our understanding of possible phreatic eruption mechanisms (e.g., Mannen et al. 2018; Ueda et al. 2018; Stix and de Moor, 2018; Battaglia et al. 2019).

Phreatic eruptions may be regarded as relatively small events from a view of the total ejected material amount (VEI: Volcano Explosive Index, Newhall and Self, 1992), with the VEI of 0-2 (e.g., Brown and Lawless, 2001; Mayer et al. 2015; Maeno et al. 2016; Geshi and Itoh 2018; Mannen et al. 2018, The Joint Research Team for ash fall in Kusatsu-Shirane 2018 eruption, 2018). However, phreatic eruptions and related unrest activities often excite seismic signals and transient ground deformation with considerable amplitudes (e.g., Aoyama and Oshima 2008, 2015; Maeda et al. 2015). Previous studies have demonstrated that seismic analysis is vital for understanding the phreatic eruption mechanism and related hydrothermal activities with locations, force system, and its temporal changes of seismic wave sources (e.g., Jolly et al. 2010, 2018; Kato et al. 2015; Maeda et al. 2015; Yukutake et al. 2017). Amplitude Source Location (ASL) method has been applied at numerous volcanoes to constrain the source location of volcanic tremor (e.g., Yamasato, 1997; Battaglia and Aki 2003, Kumagai et al. 2010; Kurokawa et al. 2016; Ichihara and Matsumoto 2017; Ichimura et al. 2018; Walsh et al. 2019). Since no investigation has been reported at Motoshirane in terms of geophysical ground observations, our primary objective is to locate the hydrothermal system that drove the 2018 phreatic eruption. We apply the ASL technique to seismic records accompanying the 2018 eruption to estimate volcanic tremor source locations. The relation between our result and the hydrothermal system structures of Kusatsu-Shirane is discussed to illustrate the source process of the 2018 eruption.

\section{Observation networks}

Kusatsu-Shirane Volcano Observatory (KSVO), Volcano Fluid Research Center, Tokyo Institute of Technology, has conducted seismic observation at Kusatsu-Shirane since 1990 (Mori et al. 2006). The seismic network of KSVO focuses on the Shirane cone, the center for active seismicity in Kusatsu-Shirane (Fig. 1c). We adopt seismic data recorded at KSE, KSS, KSW, KSYG, JIE, and infrasound data at KSRH. National Research Institute for Earth Science and Disaster Resilience (NIED) also has a multiparametric observation network (V-net) at KusatsuShirane since 2014 (Tanada et al. 2017). Seismic and tilt data obtained by borehole instruments at KSHV, KSYV, and KSNV (Fig. 1b) are adopted in this paper. We also analyze ground velocity and infrasound data recorded 
at KSAO and KSHA (Fig. 1c), operated by Japan Meteorological Agency (JMA). All adopted seismometers have a natural frequency of $1 \mathrm{~Hz}$. Table 1 summarizes our dataset.

\section{Seismicity and hydrothermal system structures at Kusatsu-Shirane}

Figure 2a shows hypocenter distributions of volcanic earthquakes at Kusatsu-Shirane routinely determined by KSVO. Two earthquake clusters characterize the seismicity at Kusatsu-Shirane: the major one is beneath the Yugama lake (Yugama cluster) at a depth of $500-1700 \mathrm{~m}$. Most events in Fig. 2 are Volcanic Tectonic (VT) type, although some events in the Yugama cluster are LongPeriod (LP) events which may be ascribed to a fluiddriven mechanism (Nakano et al. 1998, 2003; Kumagai et al. 2002; Fujita and Ida 2003). Another cluster can be found beneath the Ainomine cone (Ainomine cluster). Since no seismic station covers the south of Ainomine (Fig. 1 and 2) up to the 2018 eruption (Yamamoto et al. 2018), the precision of hypocenter determination for the Ainomine cluster may be less than that of the Yugama cluster. The number of volcanic earthquakes significantly decreases below sea level (Fig. 2a). This low seismicity region corresponds reasonably to a conductive region detected by Audio-magnetotelluric (AMT) (Nurhasan et al. 2006) and magnetotelluric (MT) surveys (Matsunaga et al. 2020; Tseng et al. 2020) at a depth of $1-3.5 \mathrm{~km}$ from the surface. The conductor is interpreted as a hydrothermal fluid reservoir, supplying hydrothermal fluid for thermal springs, fumaroles, and lake waters at KusatsuShirane as inferred by geochemical studies (Hirabayashi 1999; Ohba et al. 2000; Ohwada et al. 2003). Therefore, a plausible interpretation for seismicity above the fluid reservoir is that ascending hydrothermal fluid induces small earthquakes (Nurhasan et al. 2006; Tseng et al. 2020). The Motoshirane cone had the latest lava effusion at the Kusatsu-Shirane $\sim 1500$ years ago (Nigorigawa et al.
2016). In addition, some small craters at the summit area of Motoshirane suggest the possibility of unconfirmed phreatic eruptions after the last lava effusion (Fig. 1c, Geospatial Information Authority of Japan, 2018). The flank of the Motoshirane produces thermal springs with a total discharge energy of $110 \mathrm{MW}$ (Ueki and Terada 2012). Although this value is substantial for non-eruptive volcanism (Kagiyama 1981), no specific seismic activities are related to their features (Fig. 2a).

Focusing on volcanic activity of Kusatsu-Shirane in the last few decades, the first unique event after the 1989-1991 unrest (Takahashi and Fujiwara, 2014; Terada 2018) includes a transient ground inflation-deflation event accompanying volcanic tremor on January 2011 (the 2011 unrest) beneath the Ainomine peak (Terada et al. 2011; Fujiwara et al. 2011). From March 2014, major seismic swarms started around Yugama (Kuwahara et al. 2016), along with ground inflation, changes in the total magnetic field, temperature, and geochemical components in lake water (Terada et al. 2016; Ohba et al. 2016). Figure $2 b$ shows the time history of seismicity at Kusatsu-Shirane from June 2016 to December 2018. The beginning of the time window in Fig. $2 \mathrm{~b}$ corresponds to unrest from 2014, and that has been gradually diminishing. Apart from the phreatic eruption on 23 January 2018, a new series of the seismic swarm began at Yugama in April 2018. No eruption related to this unrest occurred up to May 2020 (JMA, 2020).

\section{The 2018 phreatic eruption}

We plot seismic, tilt, and infrasound records from 09:58 to $10: 05$ on 23 January 2018 (all times in JST in this paper), including signals accompanying the 2018 eruption in Fig. 3. Volcanic tremor appears on a raw ground velocity record at KSW from 9:59:35 (Fig. 3a). Tremor amplitude decreases from 10:01:30, and another wave group follows with a larger amplitude (10:02:10). Fourier spectra of seismic signals in Fig. 3a (from 09:58:20)

Table 1 Instruments details of seismic networks at Kusatsu-Shirane volcano

\begin{tabular}{|c|c|c|c|c|c|}
\hline & Station & Sensor & $\begin{array}{l}\text { Natural } \\
\text { period/flat } \\
\text { response }\end{array}$ & Sampling & Data logger/resolution \\
\hline \multirow[t]{5}{*}{ Short period seismometer } & KSE, KSS, and KSW (KSVO) & JTS-33 (Akashi) & $1 \mathrm{~s}$ & $200 \mathrm{~Hz}$ & LS-7000XT (Hakusan) / 22 bit \\
\hline & KSYG and JIE (KSVO) & L4 (Mark Product) & $1 \mathrm{~s}$ & $200 \mathrm{~Hz}$ & LS-7000XT (Hakusan) / 22 bit \\
\hline & KSHV, KSNV, and KSYV (NIED) & JTS-33 (Mitsutoyo) & $1 \mathrm{~s}$ & $100 \mathrm{~Hz}$ & HKS-9200/9300 (Keisokugiken) / 27 bit \\
\hline & $\mathrm{KSAO}(\mathrm{JMA})$ & JTS-23 (Mitsutoyo) & $1 \mathrm{~s}$ & $100 \mathrm{~Hz}$ & S502G (Meisei) / 24 bit \\
\hline & KSHA (JMA) & L4-C (Mark Product) & $1 \mathrm{~s}$ & $100 \mathrm{~Hz}$ & LS-7000XT (Hakusan) / 24 bit \\
\hline \multirow[t]{2}{*}{ Infrasound microphone } & KSRH (KSVO) & SI-102 (Hakusan) & $0.05-100 \mathrm{~Hz}$ & $200 \mathrm{~Hz}$ & LS-7000XT (Hakusan) / 22 bit \\
\hline & $\mathrm{KSAO}(J M A)$ & ACO 3348 (Aco) & $0.1-100 \mathrm{~Hz}$ & $100 \mathrm{~Hz}$ & TYPE 7144 (Aco) / 16 bit \\
\hline Tiltmeter & KSHV, KSNV, and KSYV (NIED) & JTS-33 (Mitsutoyo) & $\mathrm{DC}-5 \mathrm{~Hz}$ & $20 \mathrm{~Hz}$ & HKS-9200/9300 (Keisokugiken) / 27 bit \\
\hline
\end{tabular}




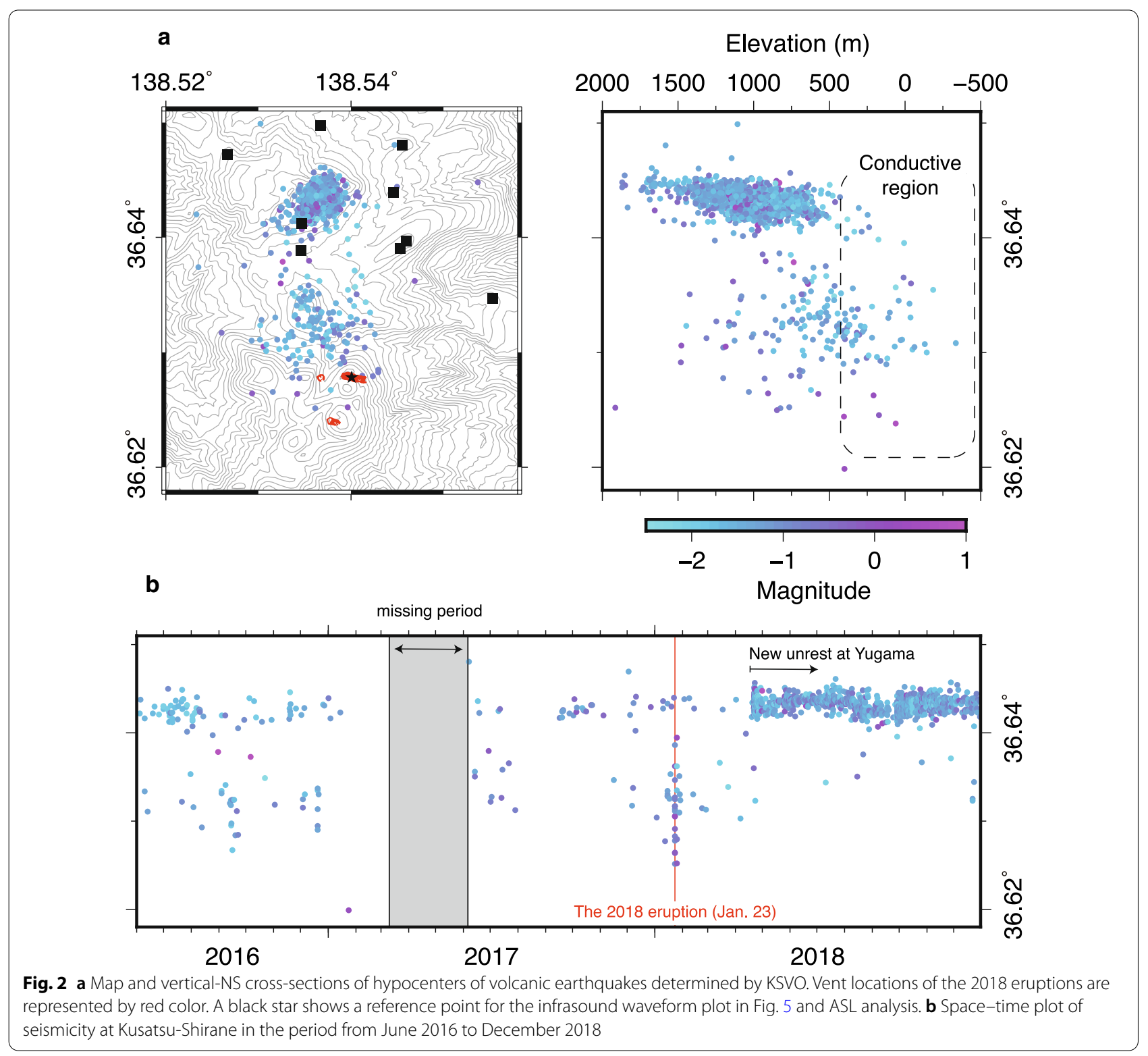

and background signals before the onset of tremor (from 09:50:00) are denoted in Fig. 4a. The frequency content of seismic signals associated with the 2018 eruption has a broad peak range from $0.5 \mathrm{~Hz}$ to $30 \mathrm{~Hz}$. A better view for understanding the frequency content is obtained from amplitude ratios to background time window in Fig. $4 \mathrm{~b}$. We see that there are broadly two major signal peaks in frequency bands of $1-2 \mathrm{~Hz}$ and $3-30 \mathrm{~Hz}$. To examine temporal intensity changes, we apply causal band-pass filters with two corresponding cut-off frequency bands $(0.5-5 \mathrm{~Hz}$, and $5-20 \mathrm{~Hz})$ on raw vertical ground velocity in Fig. 3b. The dividing frequency range from $5 \mathrm{~Hz}$ in Fig. $3 \mathrm{~b}$ is related to our analysis in the following section.
A filtered waveform in the $0.5-5 \mathrm{~Hz}$ band has an almost identical time history with a raw waveform. On the other hand, another filtered $(5-20 \mathrm{~Hz})$ waveform shows a different time-series of amplitude; it has signals with a considerable amplitude on 09:59-10:01 as well as raw and the $0.5-5 \mathrm{~Hz}$ filtered waveforms, but has fewer signals on the second impulsive wave group from 10:02:10.

Tilt records at KSHV are shown in Fig. 3c. To emphasize dynamic ground deformation, we apply an acausal low-pass filter with a cut-off frequency of $0.05 \mathrm{~Hz}$ on tilt records in Fig. 3c. We see that an east-northward uplift begins almost simultaneously with volcanic tremor. Since the station KSHV is on the west-southwest side 


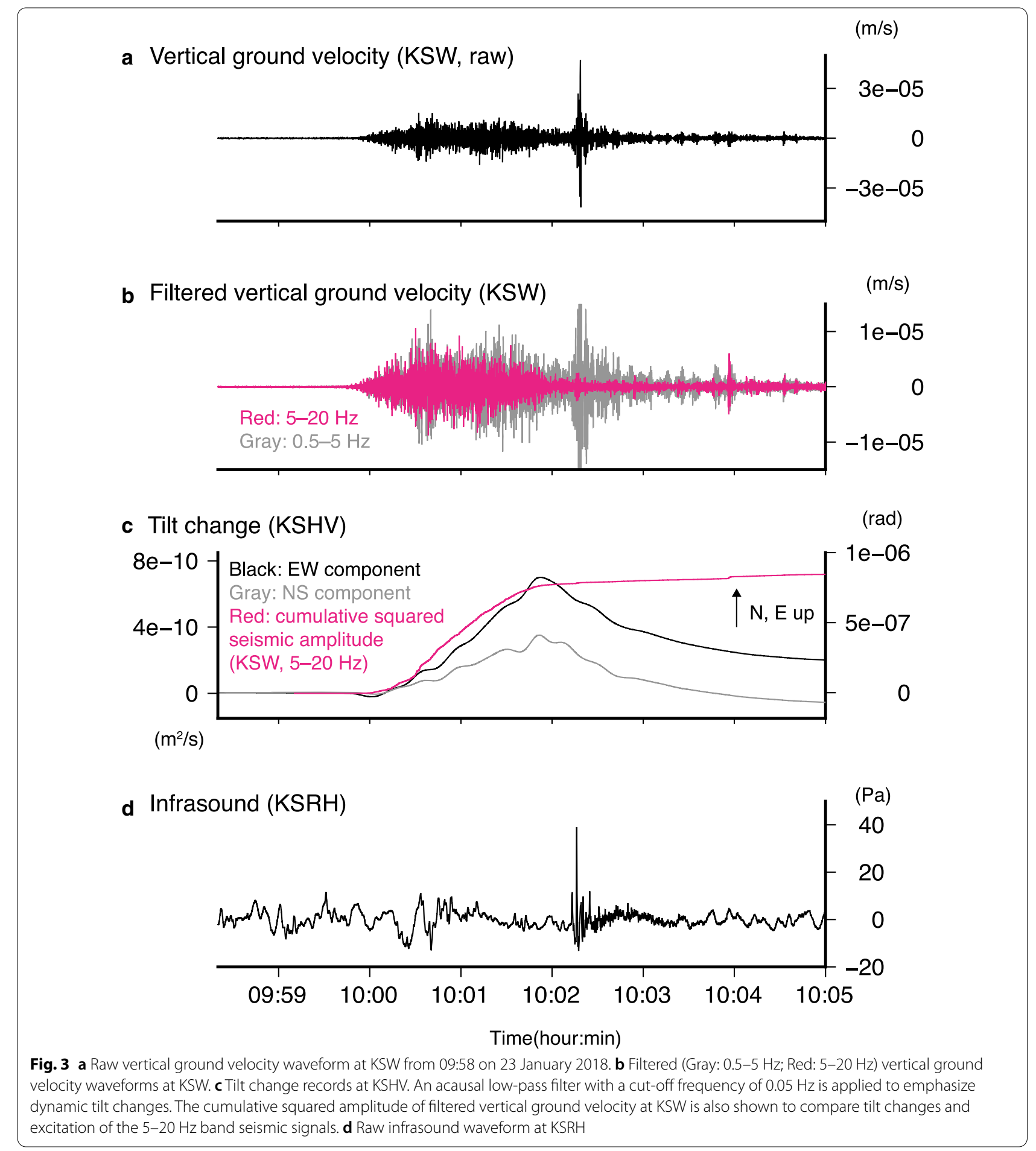

flank of Motoshirane, the tilt change from 10:00 can be interpreted as inflation of the Motoshirane cone (Terada et al. 2018). The polarity of tilt change turns to the opposite at 10:01:50. This timing coincides with a reduction of tremor in the $5-20 \mathrm{~Hz}$ signals. We also plot the cumulative squared amplitude of filtered (5-20 Hz) vertical ground velocity at $\mathrm{KSW}$ in Fig. 3c. Both volcanic tremor in the $5-20 \mathrm{~Hz}$ band and the inflation occur within almost identical time windows. 


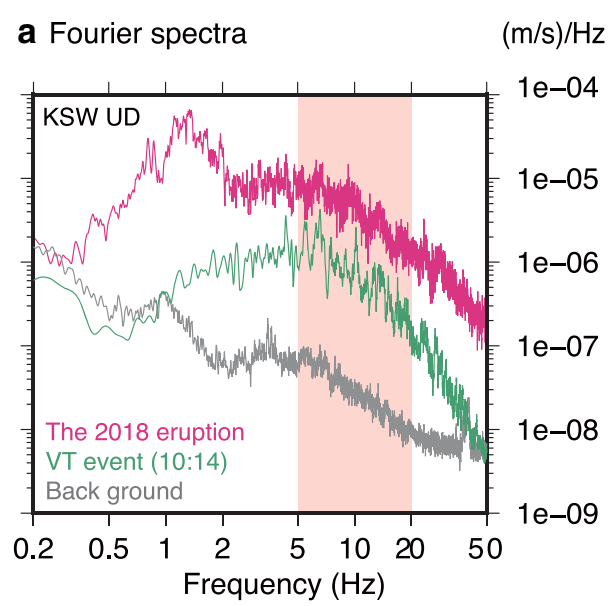

b Ratio to background time window $\mathrm{dB}$

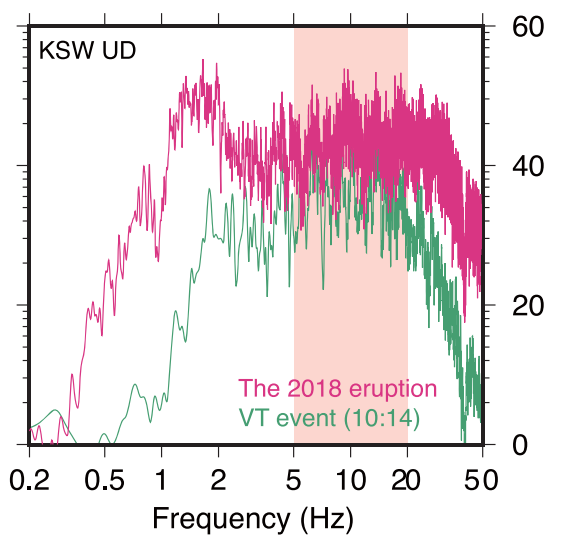

Fig. 4 a Fourier spectra for the vertical ground velocity at KSW (Red: for 500 s from 09:58:19; Green: for 100 s from 10:14:09; Gray: for $500 \mathrm{~s}$ from 09:50:00). Pink color corresponds to the frequency band of $5-20 \mathrm{~Hz}$, which is focused on our ASL analysis. b Spectrum ratios to background signals

Figure 3d shows the raw infrasound waveform at KSRH. Although the waveform contains noise signals probably derived from wind, there is a distinct wave group from 10:02:13 with a greater amplitude than the background level. To examine the infrasound origin time, we plot raw infrasound records at KSRH and KSAO from 10:02:00 in Fig. 5. Although the signal-to-noise ratio (SNR) of infrasound record at KSAO is relatively low, we find coherent signals on both infrasound waveforms from $12 \mathrm{~s}$ in Fig. 5. Arrival times of signals in both waveforms can be explained assuming that the signals propagate from the center of active vents of the 2018 eruption (Fig. 2a) with an apparent velocity of $340 \mathrm{~m} / \mathrm{s}$, which is consistent with the sound velocity near the ground. Hence, we consider the origin time of infrasound is 10:02:09. This estimation is consistent with a report by ERI (2018), which examined the coherence of seismic and infrasound signals (Ichihara

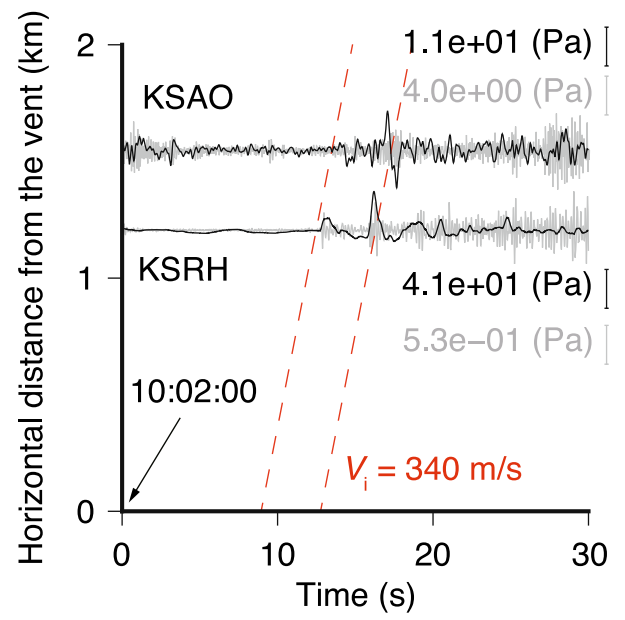

Fig. 5 Raw (black) and filtered ( $5-20 \mathrm{~Hz}$, gray) infrasound records at $\mathrm{KSRH}$ and KSAO. The origin time of the horizontal axis is 10:02:00. The vertical offset of each waveform denotes horizontal distances from the center of active vents of the 2018 eruption denoted in Fig. 2a. Red broken lines show an apparent propagation velocity $\left(V_{i}\right)$ of $340 \mathrm{~m} / \mathrm{s}$

et al. 2012). The infrasound origin time also implies that the second wave group on seismic record (Fig. 3a) is associated with surface activity with ash and gas emissions.

\section{ASL method for the $\mathbf{2 0 1 8}$ eruption}

Our inspection of observed data associated with the 2018 eruption shows that volcanic tremor precedes the onset of eruption for $2 \mathrm{~min}$. Now, we apply the ASL technique to seismic records to estimate volcanic tremor source locations. Here, analyzed seismic signals are assumed as body waves from a point source having an isotropic radiation pattern with wave scattering in the medium. From this assumption, ground velocity amplitude at $r_{i} \mathrm{~km}$ away from the seismic source, $A\left(r_{i}\right)$, can be expressed as:

$$
A\left(r_{i}\right)=\frac{A_{0} S_{i}}{r_{i}} \exp \left(-B r_{i}\right), B=\frac{\pi f}{\beta Q},
$$

where $A_{0}$ is source amplitude, $S_{i}$ is site amplification factor, $f$ is the center frequency of analyzed signals, $\beta$ is the $S$-wave velocity in the medium, and $Q$ is the quality factor for medium attenuation (Aki and Richards 2002). The subscript $i$ corresponds at the $i$ th station in the network. The assumption for isotropic $S$-wave radiation is valid for signals with frequencies higher than $5 \mathrm{~Hz}$ (Takemura et al. 2009; Kumagai et al. 2011). Hence, we focus on ground velocity in the band of $5-20 \mathrm{~Hz}$, which is almost identical to one of the dominant frequency ranges in observed seismic records (Fig. 4). A homogeneous $S$-wave velocity of $\beta=2.42 \mathrm{~km} / \mathrm{s}$ is referred from Kuwahara et al. (2016), who examined seismic velocity structures at Kusatsu-Shirane with travel times of 
volcanic earthquakes. The quality factor $Q$ is set at 50 as a representative value at active volcanoes (e.g., Koyanagi et al. 1995; Battaglia and Aki 2003; Morioka et al. 2017). We adopt seismic records at KSE, KSS, KSW, KASO, and KSHA in the ASL based on the observed SNR, distances from the Motoshirane cone, and operational history, including the 2011 unrest. The ASL determines the source location by minimizing residuals between observed and modeled amplitudes by Eq. 1. However, since no seismic station covers the south of Motoshirane, the grid search for minimum residual needs to be modified to suit our network configuration. Hence, we follow an improved version of the ASL proposed by Ichihara and Matsumoto (2017) for searching the minimum residual and $S_{i}$ determination. Their method evaluates residuals with amplitude ratios of each station pair. Ratios of observed $\left(R_{i j}^{\text {obs }}\right)$ and modeled $\left(R_{i j}^{\text {model }}\right)$ amplitudes from Eq. 1 of each station pair are defined as:

$$
R_{i j}^{\mathrm{obs}}=\frac{A_{i}^{\mathrm{obs}}}{A_{j}^{\mathrm{obs}}}, \quad R_{i j}^{\text {model }}=\frac{S_{i} r_{i}^{-1} \exp \left(-B r_{i}\right)}{S_{j} r_{j}^{-1} \exp \left(-B r_{j}\right)},
$$

where $A_{i}^{\text {obs }}$ is a band-passed Root-Mean-Squared (RMS) amplitude in each time window for $10 \mathrm{~s}$. By adopting Eq. 2 for the grid search, observed seismic traces with smaller amplitudes could minimize residuals equally along with traces with larger amplitudes. Diminishing a parameter of $A_{0}$ in Eq. 2 improves the robustness of the analysis. Therefore, we regard the error evaluation with amplitude ratio as an improvement over the amplitude only approach (Battaglia and Aki 2003). The residual between observed and modeled amplitude ratios is defined as:

$$
R E S=\sqrt{\frac{2}{N(N-1)} \sum_{i=1}^{N-1} \sum_{j=i+1}^{N}\left(\frac{R_{i j}^{\mathrm{obs}}-R_{i j}^{\text {model }}}{R_{i j}^{\mathrm{obs}}}\right)}
$$

Each time window is shifted for $10 \mathrm{~s}$ without overlapping each other.

Equation 1 shows that $S_{i}$ at each station is critical for source location determination with the ASL. $S_{i}$ values are often determined with a coda-normalization method using far-field earthquakes (Phillips and Aki, 1986; Mayeda et al. 1991). However, amplitude variations of observed coda-wave affect the estimation of $S_{i}$, causing potential errors for source location estimates (Ogiso et al. 2016; Walsh et al. 2017). Following Ichihara and Matsumoto (2017), the present study determines $S_{i}$ setting a reference time window that the source location is fixed at a certain point. Tremor source location is often estimated at the surface of the vent during eruptions (Battaglia et al. 2005; Yukutake et al. 2017). Therefore, our reference time window is set from 10:02:10, including the origin time of dominant infrasound signals, and with source location at the surface of the center of active vents (Fig. 2a). The maximum infrasound amplitude in the $5-20 \mathrm{~Hz}$ band is about $1 \mathrm{~Pa}$ (Fig. 6). Following Ichihara et al. (2012), this pressure change can induce ground velocity on the order of $10^{-7} \mathrm{~m} / \mathrm{s}$, which is one order of magnitude smaller than the observed tremor amplitude in the reference time window (Fig. 3). Seismometers at KSE, KSS, KSW, and KSAO are borehole-type and installed at a depth of 50-200 m from the surface (Mori et al. 2006; Saito et al. 2013; Tanada et al. 2017). Therefore, we consider that the effect of infrasound propagation on seismic records is negligible. Figure 6a shows RES values for the reference
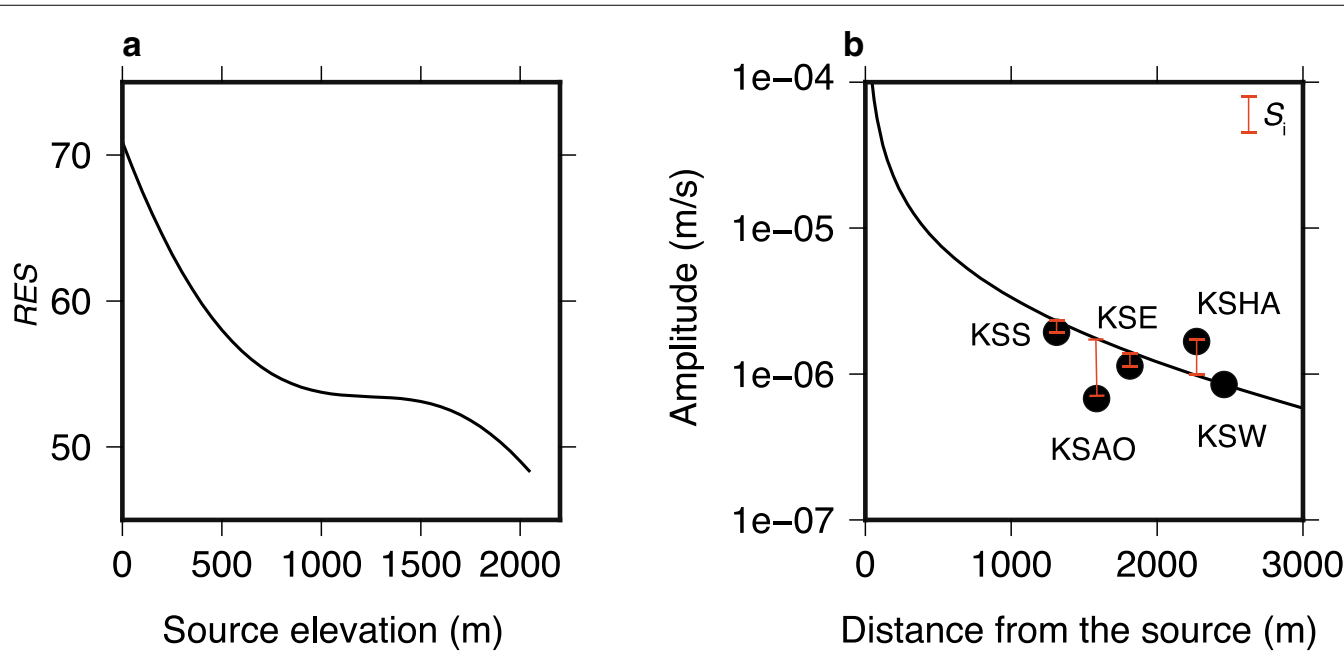

Fig. 6 a Residual values (RES) with different sour elevations beneath the crater setting $S_{i}$ as 1 . b Modeled amplitude at an elevation of $2050 \mathrm{~m}$ (the ground surface) for the reference time window. Red bars correspond to values of $S_{i}$ at each station 
time window with different reference source elevations beneath the vent without considering $S_{i}$ (setting $S_{i}$ as 1 ). The minimum value of $R E S$ is obtained at the ground surface (an elevation of $2050 \mathrm{~m}$ ). Hence, we consider the assumption of a fixed reference source location at the surface as acceptable, although our network configuration is not ideal with insufficient stations at the Motoshirane and Ainomine peaks. Corresponding modeled amplitudes by Eq. 1 are denoted in Fig. 6b with observed filtered RMS amplitudes of the reference time window. The source amplitude of $A_{0}$ is calculated to explain the observed RMS amplitude at KSW for each grid node and time window. This choice of $A_{0}$ is based on the borehole instrument at KSW, which is installed in the host rock (Uto et al. 2004). Here, the vertical seismic records show the lowest amplification in the network based on the coda-normalization method (Additional file 1: Table S2). Hence, $S_{i}$ at other stations is determined to satisfy the modeled amplitudes in the reference time window in Fig. 6b.

Searching for the minimum RES is conducted with a grid size of $10 \mathrm{~m}$. We set a search range from elevations of $-1500 \mathrm{~m}$ to the surface, latitudes of 36.618-36.651, and longitudes of 138.524-138.558, which covers the relevant area of the Motoshirane and Shirane cones. The 2018 eruption affected the local electricity supply network with ashfall, and it caused data loss at KSE, JIE, KSYG, and KSHA after 10:02:40. Therefore, we focus on the time window for $210 \mathrm{~s}$ from 09:59:00.

\section{Result}

Figure 7a represents horizontal tremor locations obtained by our ASL analysis. The color of each plot indicates the time, as shown in a color palette of Fig. $7 \mathrm{~b}$. Filtered (5-20 Hz) vertical ground velocity at KSW, estimated source elevation, and the minimum RES value for each time window are denoted in Fig. 7b. A source location plot surrounded by a green square (190 s) is the reference window that the source is fixed at the surface of the vent. Inferred tremor locations up to $170 \mathrm{~s}$ are ranging about $500 \mathrm{~m}$ east of the Ainomine peak. Corresponding elevations are in the range of $1.0-1.5 \mathrm{~km}$, equivalent to a depth of $0.5-1 \mathrm{~km}$ from the ground surface. Inferred source locations suddenly move to the south in $180 \mathrm{~s}$. After the reference window in $190 \mathrm{~s}$, source locations are estimated at near the ground surface around Motoshirane. For evaluating the reliability of source location estimates, Fig. 8 shows a representative example of $R E S$ values in horizontal and vertical cross-sections of a time window of $120 \mathrm{~s}$ (Fig. 7). If we set an error range of $0.1>R E S$, the range corresponds $-110-130 \mathrm{~m}$ in the NS direction and $-50-60 \mathrm{~m}$ in the EW direction in

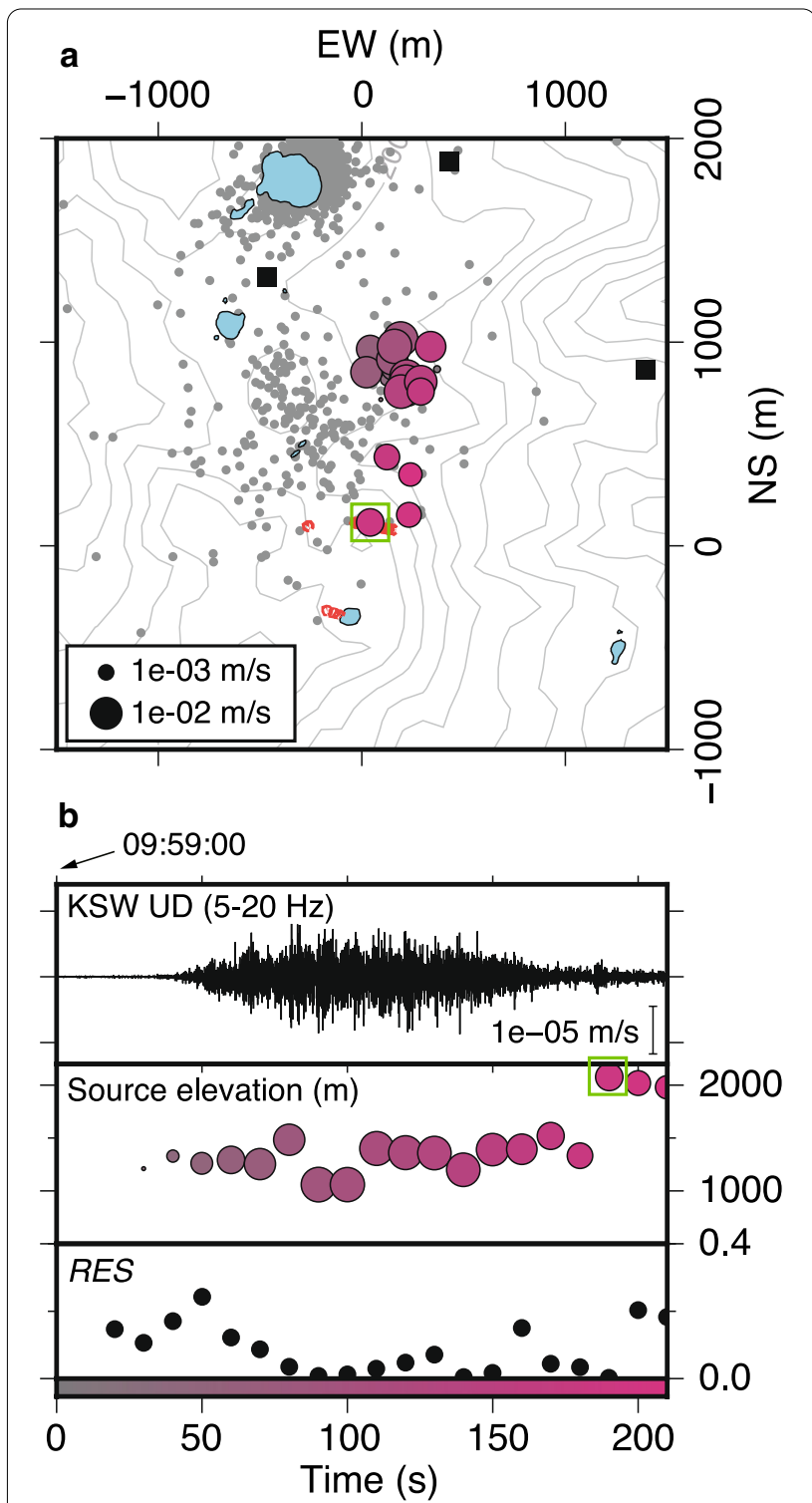

Fig. 7 a Locations of estimated tremor source. The color of each plot corresponds to a contour bar in $\mathbf{b}$. Gray dots also show epicenters of volcanic earthquakes in Fig. 2. A plot with a green square is the fixed source location for the reference time window. b Analyzed filtered $(5-20 \mathrm{~Hz})$ vertical ground velocity at KSW, estimated source elevations, and the minimum RES value of each time window. The origin time of the horizontal axis is 09:59:00

horizontal cross-section. On the other hand, the error range in vertical cross-sections is $-200-300 \mathrm{~m}$. One possible explanation of relatively poor constraint on source elevation may be derived from the station configuration, which is not ideal. Therefore, inferred tremor source elevations may include potential errors with several hundred meters. 


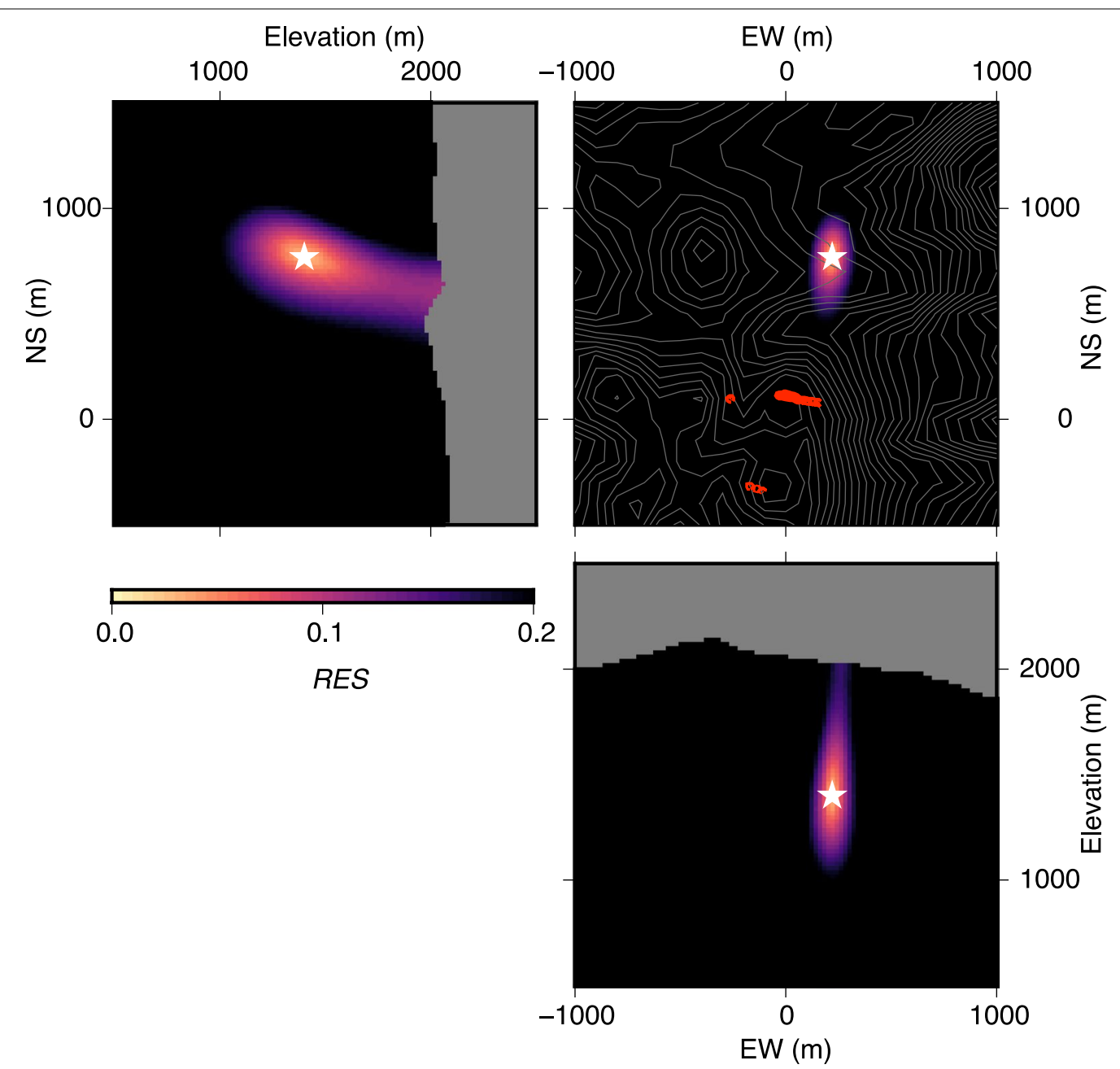

Fig. 8 Spatial distributions of RES values in map and cross-sections through the point (star) with the minimum RES value for a time window of $120 \mathrm{~s}$ in Fig. 7. Red plots represent vent locations of the 2018 eruptions

We also conduct the ASL analysis with different $S$-wave velocity and $Q$ values to assess how our ASL locations are affected by the related elastic media parameters. If we adopt $\beta$ as $1.43 \mathrm{~km} / \mathrm{s}$ from Ida et al. (1989), the ASL yields source location at an elevation of $40 \mathrm{~m}$ higher and $70 \mathrm{~m}$ south compared to the result in the window of $120 \mathrm{~s}$ in Fig. 8. Adopting different $Q$ values (40 and 60 ) changes inferred source locations for $\pm 30 \mathrm{~m}$. Therefore, we conclude that the location dependence on the elastic media parameters is limited.

To validate our determination of $S_{i}$ at each station, we also conduct the ASL with $S_{i}$ obtained with the codanormalization method with different station configuration (Additional file 1: Fig. S2). Additional file 1: Table S2 compares estimated $S_{i}$ values with different methods. A higher amplification at KSHA, where the sensor is installed on the surface, is recognized in both results. However, a considerable disagreement is that the largest
$S_{i}$ is obtained at KSW among the borehole-type stations if we fix the reference source at the surface of the vent (Fig. 6b), while $S_{i}$ at KSW is the lowest by the coda-normalization method (Additional file 1: Table S2). A similar disagreement has been reported by Walsh et al. (2017), who examined the difference of $S_{i}$ estimates between the coda-normalization and active seismic source experiment results. Although $S_{i}$ values potentially include such uncertainties in estimation methods, the horizontal tremor locations in Additional file 1: Fig. S2 are identical to those of the main result in Fig. 7. Therefore, we consider our ASL approach to be robust.

\section{Discussion}

\section{Interpretation for examined volcanic tremor and eruption} process

Seismic signals in the $5-20 \mathrm{~Hz}$ band are usually excited by VT events with faulting mechanisms at active volcanoes 
(Nishimura and Iguchi, 2011). Figure 4b shows the considerable agreement of frequency content between the examined volcanic tremor and a VT event after the eruption (10:14). We interpret the $5-20 \mathrm{~Hz}$ band seismic signals of volcanic tremor as a superposition of small shear fractures based on this frequency content correspondence. Voight (1988) proposed the material Failure Forecast Model (FFM) that explains accelerating precursory signals of volcanic eruptions with a general material failure law. Following the approach of Chardot et al. (2015), we conduct the FFM analysis for the $5-20 \mathrm{~Hz}$ signals at KSW to assess our interpretation. Additional file 2 : Fig. S3 shows the FFM predicts the failure in 10:00:10-10:01:00. Although this prediction is $\sim 2$ min earlier than the onset of the eruption (10:02:09), it can be interpreted alternatively as the time of the subsurface cap-rock failure: when the cap-rock layer is no longer capable of restricting the over-pressurized fluid and proceeds to the vertical fluid migration. The predicted timing relates to the beginning of inflation (Fig. 3). Sudden expansion by boiling of the migrated hydrothermal fluid is a plausible scenario for inducing the ground deformation preceding phreatic eruptions. We estimate fluid advection velocity is about $\sim 10 \mathrm{~m} / \mathrm{s}$ by considering the lapse time $(\sim 2 \mathrm{~min})$ and the tremor source-vent distance $(1.1-1.4 \mathrm{~km})$. This estimate is almost comparable with VT hypocenter migration $(\sim 5 \mathrm{~m} / \mathrm{s})$ prior to the 2014 phreatic eruption at Ontake (Kato et al. 2015) and slightly faster than numerical investigation $(0.25-2.9 \mathrm{~m} / \mathrm{s})$ at White island by Jolly et al. (2018).

The hydrothermal fluid behaviors can also excite seismic activity (Chouet 1986; Julian 1994; Rust et al. 2008). Geysers and fumaroles can excite seismic signals with frequencies higher than $10 \mathrm{~Hz}$ (Motoya and Nogoshi, 1962; Kedar et al. 1996). Hence, a superposition of fault slips may not be a unique mechanism for the examined seismic signals. However, seismic wave excitation from hydrothermal fluid behaviors are often related to signals with lower frequency ranges, such as $<0.5 \mathrm{~Hz}$ (e.g., Fujita and Ida, 2003; Ohminato, 2006; Maeda et al. 2013). This signal range is also similar to another frequency peak range of observed ground velocity (Fig. 4), which has a significantly larger amplitude around the eruption onset (Fig. 3b). Hence, we prefer small shear fractures as a mechanism of examined tremor signals.

Our ASL method estimates volcanic tremor source locations at about $500 \mathrm{~m}$ east and the depth of $0.5-1 \mathrm{~km}$ beneath the Ainomine cone. This region is slightly east and within the upper portion of the Ainomine cluster (Fig. 2). Hypocenters of volcanic earthquakes with a different station configuration and seismic velocity model from the present routine of KSVO are reported by Mori et al. (2006). Their epicenter distributions match closely with tremor locations from our ASL. Note that inferred tremor locations are relative to the reference point fixed at the surface of the vent. However, the comparison between our result and the earlier hypocenter distributions by Mori et al. (2006) suggests that the tremor is related to the seismogenic zone beneath Ainomine. According to AMT (Nurhasan et al. 2006) and MT soundings (Matsunaga et al. 2020; Tseng et al. 2020), the eastern flank of Kusatsu-Shirane is covered by a conductive layer with a thickness of $0.3-1 \mathrm{~km}$. Drilling surveys reveal that the conductive layer consists of smectite with an impermeable characteristic (Kurasawa 1993). A low permeable structure, often known as a cap-rock, is essential to seal vertical fluid flow for hosting a hydrothermal system. The focal depth of volcanic earthquakes can support the sealing structure by the caprock beneath Ainomine. Most earthquakes in the Ainomine cluster occur below an elevation of $1 \mathrm{~km}$ (Fig. 2). Pre-eruption conditions may be interpreted as a result of the low flow rate of hydrothermal fluid into a steady-state impermeable cap-rock, resulting in intermittent seismic events beneath the Ainomine. Based on the above signal characteristics and background, it is plausible to assume that sudden and unusual hydrothermal fluid injection for the cap-rock layer beneath Ainomine occurred, which induced the small shear fractures in the cap-rock observed as volcanic tremor (Fig. 9).

Notably, the pre-eruption seismic signals in the $5-20 \mathrm{~Hz}$ band are also accompanied by the rapid inflation of Motoshirane. This correspondence is also widely reported associated with phreatic eruptions and unrests at other volcanoes, such as Kuchinoerabujima (Tameguri et al. 2016; Nakamichi et al. 2016), Ontake (Kato et al. 2015), Hakone (Honda et al. 2018; Yukutake et al. 2018), Meakan-dake (Aoyama and Oshima 2008, 2015), and Hokkaido-Komagatake (Usu Volcano Observatory, 1997). In volcanic settings, sudden ground inflation is often inferred as an expansion of super-heated underground water, which may trigger phreatic eruptions (Maeda et al. 2017; Stix and de Moor 2018). Himematsu et al. (2020) detected syn-eruptive and posteruptive subsidence of Motoshirane with Synthetic Aperture Radar (SAR) data. Although we do not estimate the deformation source location with tilt records in this paper, ground deformation obtained with the spaceborne observation by Himematsu et al. (2020) suggests that the deformation source beneath the Motoshirane induced the tilt change. Therefore, a possible scenario to explain observed volcanic tremor and ground inflation is that injected hydrothermal fluid beneath Ainomine migrated laterally at a certain depth and induced the deformation beneath Motoshirane (Fig. 9).

\section{Implications for the hydrothermal system structure of Kusatsu-Shirane volcano}

The Yugama and Ainomine clusters of volcanic earthquakes have been recognized from seismic observation in the 1980s (Ida et al. 1989). Ida et al. (1989) interpreted 


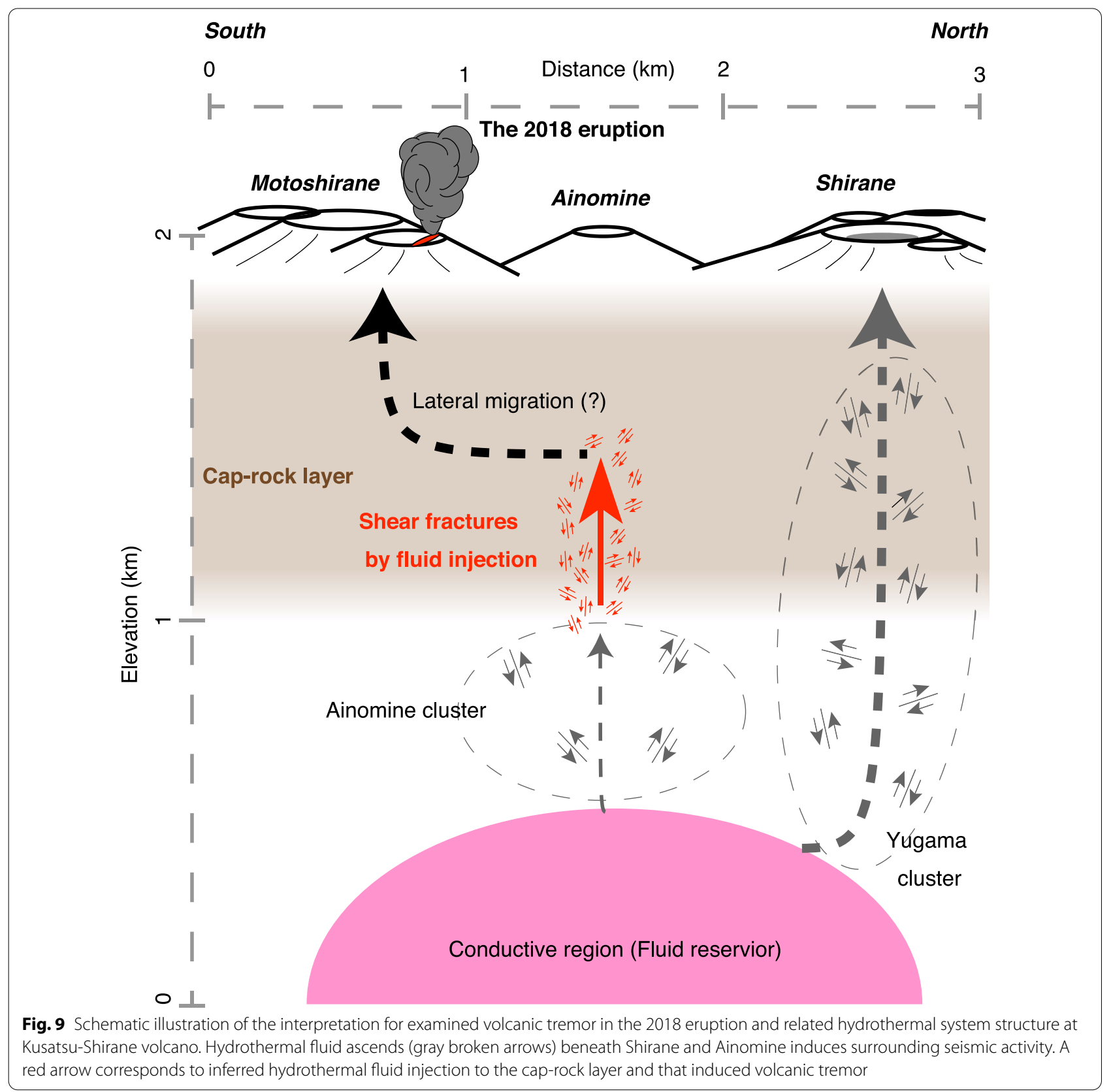

that the Ainomine cluster can be a part of the fluid pathway from source to beneath Yugama, considering the focal depth differences. Along with seismic records of the 2018 eruption, we also apply the same ASL analysis to the 2011 unrest (Additional file 3: Fig. S4). Inferred tremor locations are almost identical to that of the 2018 eruption, which does not overlap the Yugama cluster. This coincidence of tremor locations suggests that the 2011 unrest shared the same triggering mechanism as the 2018 eruption. The relation between both seismic clusters can be discussed from the time-series of seismicity. Figure 2 shows no evident changes in the Yugama cluster related to the 2018 eruption at Motoshirane. The Ainomine cluster also shows no response to the series of unrest at the Yugama since April 2018. Therefore, it is reasonable to consider that both seismic clusters reflect independent hydrothermal fluid pathways from the fluid reservoir (Fig. 9). Such a perspective can contribute evaluation of volcanic activity at Kusatsu-Shirane.

Our result reveals a major triggering system of the 2018 eruption was located not beneath Motoshirane but Ainomine. Low seismicity beneath Motoshirane in the time window in Fig. $2 \mathrm{~b}$ is consistent with our interpretation. However, the present study does not 
show the nature of the lateral distance between the vent (Motoshirane) and triggering hydrothermal fluid injection (beneath Ainomine). We are also blind regarding the conditions beneath the Motoshirane before the eruption, because a few ground observations had focused on the Motoshirane cone. Previous studies at Kusatsu-Shirane have revealed some fundamental aspects of the hydrothermal system focusing on the Shirane cone. Further investigations and continuous observation targeting Motoshirane, as well as Shirane, will contribute to better understanding of the hydrothermal system beneath the Kusatsu-Shirane volcano.

\section{Conclusion}

We have examined seismic, tilt, and infrasound records accompanying the 2018 phreatic eruption at KusatsuShirane volcano to understand the source process of a unique eruption after a long dormancy of the Motoshirane cone. The onset of eruption is preceded by $\sim 2 \mathrm{~min}$ of volcanic tremor and tilt deformation. The broadspectrum of volcanic tremor is consistent with continuous microfractures accompanied by rapid inflation. We applied the ASL method for the $5-20 \mathrm{~Hz}$ band signals to determine tremor source locations. Our analysis estimates the tremor sources at $1 \mathrm{~km}$ north from Motoshirane and at a depth of $0.5-1 \mathrm{~km}$ from the surface. Inferred source locations correspond to an impermeable cap-rock layer and an upper portion of the seismogenic region beneath the Ainomine cone. Seismic signals in the 5-20 Hz band correspond to dominant signals accompanying VT events with faulting mechanism. Therefore, we interpret that the examined volcanic tremor reflects small shear fractures induced by sudden hydrothermal fluid injection for the cap-rock layer, which triggered the 2018 eruption. This interpretation is supported by the FFM adopting the volcanic tremor signals, which predicts consistent the cap-rock failure timing. Our investigation also suggests that the hydrothermal fluid injection occurred at an independent pathway from beneath the Shirane cone, which has driven a series of unrest at Yugama since 2014.

\section{Supplementary Information}

The online version contains supplementary material available at https://doi. org/10.1186/s40623-020-01349-1.

Additional file 1. Site amplification factor estimates by the coda-normalization method and corresponding ASL result.

Additional file 2. The FFM application for the $5-20 \mathrm{~Hz}$ band ground velocity at KSW.

Additional file 3. ASL result for the 2011 unrest at Kusatsu-Shirane.

\section{Abbreviations}

ASL: Amplitude Source Location; KSVO: Kusatsu-Shirane Volcano Observatory; NIED: National Research Institute for Earth Science and Disaster Resilience; JMA: Japan Meteorological Agency; VT:Volcano Tectonic; LP: Long Period; JST: Japan Standard Time; RMS: Root-Mean-Squared; GSI:The Geospatial Information Authority of Japan; AMT: Audio-magnetotelluric; MT: Magnetotelluric; SNR: Signal-to-noise ratio

\section{Acknowledgments}

Staffs of KSVO are grateful for their contribution to the continuous operation of the observation network. Discussions with Profs. Junichi Hirabayashi and Masato Iguchi were valuable for giving interpretation for our result. Suggestions by Dr. Mie Ichihara improve the ASL analysis. JMA and GSI are acknowledged for providing observation data and digital elevation map at Kusatsu-Shirane volcano. Details of instruments information of JMA was provided by Dr. Ryohei Kawaguchi in Meteorological Research Institute, JMA. Constructive comments and suggestions by two anonymous reviewers and editorial handling by A.D. Jolly improved the quality of the manuscript.

\section{Authors' contributions}

TY and AK conducted the ASL analysis for seismic data. AT, WK, and YO are in charge of continuous observation of KSVO. HA and TO have assisted the observation and data processing of KSVO. HU, TT, and TY are involved in operating of V-net at Kusatsu-Shirane. The initial outlines of this study have been discussed by TY, AT, and HA. All authors read and approved the manuscript.

Funding

The present study was partly supported by the Ministry of Education, Culture, Sports, Science, and Technology (MEXT) of Japan, under its Earthquake and Volcano Hazards Observation and Research Program, Integrated Program for Next Generation Volcano Research and Human Resource Development.

\section{Availability of data and materials}

Seismic and tilt data from NIED and JMA can be downloaded from https:// www.vnet.bosai.go.jp.

Ethics approval and consent to participate

Not applicable.

\section{Competing interests}

All authors have no competing interests.

\section{Author details}

${ }^{1}$ Disaster Prevention Research Institute, Sakurajima Volcano Research Center, Kyoto University, 1722-19 Sakurajima-Yokoyama, Kagoshima 891-1419, Japan. ${ }^{2}$ National Research Institute for Earth Science and Disaster Resilience, Tennodai 3-1, Tsukuba, Ibaraki 305-0006, Japan. ${ }^{3}$ Volcanic Fluid Research Center, School of Science, Tokyo Institute of Technology, 2-12-1 Ookayama, Meguro, Tokyo 152-8551, Japan. ${ }^{4}$ Institute of Seismology and Volcanology, Faculty of Science, Hokkaido University, N10W8, Kita-ku, Sapporo, Hokkaido 060-0810, Japan. ${ }^{5}$ Aso Volcanological Laboratory, Kyoto University, 3028 Sakanashi, Ichinomiya-machi, Aso, Kumamoto 869-2611, Japan.

Received: 9 September 2020 Accepted: 24 December 2020

Published online: 11 January 2021

\section{References}

Aki K, Richards PG (2002) Quantitative Seismology, 2nd edn. University Science Books, Sausalito, USA

Aoyama H, Oshima H (2008) Tilt change recorded by broadband seismometer prior to small phreatic explosion of Meakan-dake volcano, Hokkaido. Japan Geophys Res Lett 35:L06307. https://doi.org/10.1029/2007GL0329 88

Aoyama H, Oshima H (2015) Precursory tilt changes of small phreatic eruptions of Meakan-dake volcano, Hokkaido, Japan, in November 2008. Earth Planets Space 67:1 19. https://doi.org/10.1186/s40623-015-0289-9

Barberi F, Bertagnini A, Landi P, Principe C (1992) A review on phreatic eruptions and their precursors. J Volcanol Geotherm Res 52:231-246. https:// doi.org/10.1016/0377-0273(92)90046-G 
Battaglia J, Aki K (2003) Location of seismic events and eruptive fissures on the Piton de la Fournaise Volcano using seismic amplitudes. J Geophys Res 108:2364. https://doi.org/10.1029/2002JB002193

Battaglia J, Aki K, Ferrazzini V (2005) Location of tremor sources and estimation of lava output using tremor source amplitude on the Piton de la Fournaise volcano: 1. Location of tremor sources. J Volcanol Geotherm Res 147:268-290. https://doi.org/10.1016/j.jvolgeores.2005.04.005

Battaglia A, de Moor JM, Aiuppa A et al (2019) Insights into the mechanisms of phreatic eruptions from continuous high frequency volcanic gas monitoring: Rincón de la Vieja Volcano, Costa Rica. Front Earth Sci 6:1-20. https://doi.org/10.3389/feart.2018.00247

Browne PRL, Lawless JV (2001) Characteristics of hydrothermal eruptions, with examples from New Zealand and elsewhere. Earth Sci Rev 52:299-331. https://doi.org/10.1016/S0012-8252(00)00030-1

Chardot L, Jolly AD, Kennedy BM, Fournier N, Sherburn S (2015) Using volcanic tremor for eruption forecasting at White Island volcano (Whakaari), New Zealand. J Volcanol Geotherm Res 302:11-23. https://doi.org/10.1016/j. jvolgeores.2015.06.001

Chouet B (1986) Dynamics of a fluid-driven crack in three dimensions by the finite difference method. J Geophys Res 91:13967. https://doi.org/10. 1029/jb091ib14p13967

Earthquake Research Institute (2018) Kusatsu-shirane, Report of Coordinating Committee for Prediction of Volcanic Eruption No.140. Jpn Meteorol Agency, Tokyo. https://www.data.jma.go.jp/svd/vois/data/tokyo/STOCK kaisetsu/CCPVE/shiryo/140/140_01-1-2.pdf. Accessed 15 July 2020 (in Japanese).

Fujita E, Ida Y, Oikawa J (1995) Eigen oscillation of a fluid sphere and source mechanism of harmonic volcanic tremor. J Volcanol Geotherm Res 69:365-378. https://doi.org/10.1016/0377-0273(95)00027-5

Fujita E, Ida Y (2003) Geometrical effects and low-attenuation resonance of volcanic fluid inclusions for the source mechanism of long-period earthquakes. J Geophys Res Solid Earth 108:1-17. https://doi.org/10. 1029/2002jb001806

Fujiwara Y, Yamasato H, Ogiso M (2011) Sources of the volcanic tremor with tilt changes on 27 May 2011 at Kusatsu-Shiranesan estimated using seismic amplitudes. Abstracts of the Volcanological Society of Japan 2015 Fall Meeting: P24 (in Japanese).

Geospatial Authority of Japan (2018) Information of volcanic activity at Kusatsu-Shirane volcano. https://www.gsi.go.jp/BOUSAI/kusatsushiraneindex.html. Accessed 19 July 2020 (in Japanese).

Geshi N, Itoh J (2018) Pyroclastic density currents associated with the 2015 phreatomagmatic eruption of the Kuchinoerabujima volcano. Earth Planets Space 70:119. https://doi.org/10.1186/s40623-018-0881-x

Himematsu Y, Ozawa T, Aoki Y (2020) Coeruptive crustal deformation associated with the 2018 Kusatsu-Shirane phreatic eruption based on PALSAR-2 time-series analysis. Earth Planets Space 72:116. https://doi.org/10.1186/ s40623-020-01247-6

Hirabayashi J (1999) Formation of volcanic fluid reservoir and volcanic activity. J Hot Spring Sci 49:99-105 ((in Japanese))

Honda R, Yukutake Y, Morita Y, et al (2018) Precursory tilt changes associated with a phreatic eruption of the Hakone volcano and the corresponding source model. Earth Planets Space 70:117. https://doi.org/10.1186/ s40623-018-0887-4

Ichihara M, Matsumoto S (2017) Relative source locations of continuous tremor before and after the subplinian events at Shinmoe-dake, in 2011. Geophys Res Lett 44:10,871-10,877. https://doi.org/https://doi.org/10. 1002/2017GL075293.

Ichimura M, Yokoo A, Kagiyama T et al (2018) Temporal variation in source location of continuous tremors before ash-gas emissions in January 2014 at Aso volcano. Japan Earth Planets Space 70:125. https://doi.org/10. 1186/s40623-018-0895-4

Ida Y, Osada N, Sawada M, Koyama E, Kagiyama T (1989) Seismological study based on recently installed permanent stations and a small eruptive event on January 6, 1989 at Kusatsu-Shirane volcano. Bull Earth Res Inst 64:325-345 ((in Japanese with English abstract))

Iguchi M, Nishimura T (2011) Volcanic Earthquakes and Tremor in Japan. Kyoto Univ Press, Kyoto, Japan

Japan Meteorological Agency (2020) Kusatsu-shirane. Paper presented at 146th Meeting of Coordinating Committee for Prediction of Volcanic Eruptions. Jpn Meteorol Agency, Tokyo. https://www.data.jma.go.jp/
svd/vois/data/tokyo/STOCK/kaisetsu/CCPVE/shiryo/146/146_1-1.pdf. Accessed 15 July 2020 (in Japanese).

Jolly AD, Sherburn S, Jousset P, Kilgour G (2010) Eruption source processes derived from seismic and acoustic observations of the 25 September 2007 Ruapehu eruption-North Island, New Zealand. J Volcanol Geotherm Res 191:33-45. https://doi.org/10.1016/j.jvolgeores.2010.01.009

Jolly A, Lokmer I, Christenson B, Thun J (2018) Relating gas ascent to eruption triggering for the April 27, 2016, White Island (Whakaari), New Zealand eruption sequence. Earth Planets Space 70:1-15. https://doi.org/10.1186/ s40623-018-0948-8

Julian BR (1994) Volcanic tremor: nonlinear excitation by fluid flow. J Geophys Res 99(B6):11,859-11,877. https://doi.org/https://doi.org/10.1029/93jb0 3129

Kagiyama T (1981) Evaluation methods of heat discharge and their applications to the major active volcanoes in Japan. J Volcanol Geotherm Res 9:87-97. https://doi.org/10.1016/0377-0273(81)90016-0

Kato A, Terakawa T, Yamanaka Y et al (2015) Preparatory and precursory processes leading up to the 2014 phreatic eruption of Mount Ontake. Japan Earth Planets Space 67:111. https://doi.org/10.1186/s40623-015-0288-x

Kedar S, Sturtevant B, Kanamori H (1996) The origin of harmonic tremor at Old Faithful geyser. Nature 379:708-711. https://doi.org/10.1038/379708a0

Koyanagi S, Aki K, Biswas N, Mayeda K (1995) Inferred attenuation from site effect-corrected T phases recorded on the island of Hawaii. Pure Appl Geophys 144:1-17. https://doi.org/10.1007/BF00876471

Kuwahara T, Terada A, Yukutake Y, Kanda W, Ogawa Y (2016) Upward fluid migration accompanying earthquake swarms at Kusatsu-Shirane volcano in 2014. Abstracts of the Volcanological Society of Japan 2016 Fall Meeting: B3-23 (in Japanese).

Kumagai H, Chouet BA, Nakano M (2002) Waveform inversion of oscillatory signatures in long-period events beneath volcanoes. J Geophys Res Solid Earth 107(B11):2301. https://doi.org/10.1029/2001jb001704

Kumagai H, Saito T, O'Brien G, Yamashina T (2011) Characterization of scattered seismic wavefields simulated in heterogeneous media with topography. J Geophys Res Solid Earth 116:1-13. https://doi.org/10.1029/2010JB007718

Kurasawa T (1993) Problem with the Drilling of Geothermal Well in the South of Mt. Kusatsu-Shirane, Gunma Pref. Jour Japan Geotherm Energy Assoc 30:313-335 ((in Japanese))

Kurokawa A, Takeo M, Kurita K (2016) Two types of volcanic tremor changed with eruption style during 1986 Izu-Oshima eruption. J Geophys Res Solid Earth 121:2727-2736. https://doi.org/10.1002/2015JB012500

Maeda Y, Kumagai H, Lacson R, et al (2013) Source process of long-period seismic events at Taal volcano, Philippines: Vapor transportation and condensation in a shallow hydrothermal fissure. J Geophys Res Solid Earth 118:2832-2846. https://doi.org/10.1002/jgrb.50205

Maeda Y, Kumagai H, Lacson R et al (2015) A phreatic explosion model inferred from a very long period seismic event at Mayon Volcano, Philippines. J Geophys Res Solid Earth 120:226-242. https://doi.org/10.1002/2014J B011440

Maeda Y, Kato A, Yamanaka Y (2017) Modeling the dynamics of a phreatic eruption based on a tilt observation: Barrier breakage leading to the 2014 eruption of Mount Ontake, Japan. J Geophys Res Solid Earth 122:10071024. https://doi.org/10.1002/2016JB013739

Maeno F, Nakada S, Oikawa T, et al (2016) Reconstruction of a phreatic eruption on 27 September 2014 at Ontake volcano, central Japan, based on proximal pyroclastic density current and fallout deposits the Phreatic Eruption of Mt. Ontake Volcano in 2014 5. Volcanology. Earth Planets Space 68:82. https://doi.org/https://doi.org/10.1186/s40623-016-0449-6.

Mannen K, Yukutake Y, Kikugawa G et al (2018) Chronology of the 2015 eruption of Hakone volcano, Japan: geological background, mechanism of volcanic unrest and disaster mitigation measures during the crisis. Earth Planets Space 70:68. https://doi.org/10.1186/s40623-018-0844-2

Matsunaga Y, Kanda W, Takakura S et al (2020) Magmatic hydrothermal system inferred from the resistivity structure of Kusatsu-Shirane Volcano. J Volcanol Geotherm Res 390:106742. https://doi.org/10.1016/j.jvolgeores. 2019.106742

Mayeda K (1991) site amplification from s-wave coda in the long valley caldera region, california. Bull Seismol Soc Am 81:2194-2213

Mayer K, Scheu B, Gilg HA et al (2015) Experimental constraints on phreatic eruption processes at Whakaari (White Island volcano). J Volcanol Geotherm Res 302:150-162. https://doi.org/10.1016/j.jvolgeores.2015. 06.014 
Mori T, Hirabayashi J, Nogami K, Onizawa S (2006) A new seismic observation system at the Kusatsu-Shirane volcano. Bull Volcanol Soc Japan 53:41-47 ((in Japanese with English abstract))

Morioka H, Kumagai H, Maeda T (2017) Theoretical basis of the amplitude source location method for volcano-seismic signals. J Geophys Res Solid Earth 122:6538-6551. https://doi.org/10.1002/2017JB013997

Motoya Y, Nogushi M (1963) Tremors observed at active volcano, geyser and fumarole. Bull Volcanol Soc Japan 8(1):20-32 ((in Japanese with English abstract))

Nakamichi H, Iguchi M, Tameguri T, Sonoda T (2017) Quantification of seismic and acoustic waves to characterize the 2014 and 2015 eruptions of Kuchinoerabujima Volcano, Japan. J Nat Disaster Sci 38:65-83. https:// doi.org/10.2328/jnds.38.65

Nakano M, Kumagai H, Kumazawa M, et al (1998) The excitation and characteristic frequency of the long-period volcanic event: An approach based on an inhomogeneous autoregressive model of a linear dynamic system. J Geophys Res Solid Earth 103(B5):10,031-10,046. https://doi.org/https://doi.org/10.1029/98jb00387.

Nakano M, Kumagai H, Chouet BA (2003) Source mechanism of long-period events at Kusatsu-Shirane Volcano, Japan, inferred from waveform inversion of the effective excitation functions. J Volcanol Geotherm Res 122:149-164. https://doi.org/10.1016/S0377-0273(02)00499-7

Newhall CG, Self S (1982) The volcanic explosivity index (VEI): an estimate of explosive magnitude for historical volcanism. J Geophys Res 87:123-1238. https://doi.org/10.1029/jc087ic02p01231

Nigorikawa A, Ishizaki Y, Kametani N, Yoshimoto M, Terada A, Ueki K, Nakamura K (2016) Holocene eruption history of the Motoshirane Pyroclastic Cone Group, Kusatsu-Shirane Volcano. Abstracts of Japan Geoscience Union Meeting 2016 SVC48-11.

Nurhasan, Ogawa Y, Ujihara N et al (2006) Two electrical conductors beneath Kusatsu-Shirane volcano, Japan, imaged by audiomagnetotellurics, and their implications for the hydrothermal system. Earth Planets Space 58:1053-1059. https://doi.org/10.1186/BF03352610

Ogiso M, Yomogida K (2012) Migration of tremor locations before the 2008 eruption of Meakandake Volcano, Hokkaido, Japan. J Volcanol Geotherm Res 217-218:8-20. https://doi.org/10.1016/j.jvolgeores.2011. 12.005

Ogiso M, Matsubayashi H, Yamamoto T (2015) Descent of tremor source locations before the 2014 phreatic eruption of Ontake volcano. Japan Earth Planets Space 67:206. https://doi.org/10.1186/s40623-015-0376-y

Ohba T, Hirabayashi J, Nogami K (1994) Water, heat and chloride budgets of the crater lake, Yugama at Kusatsu-Shirane volcano, Japan. Geochem Jour 28:217-231

Ohba T, Hirabayashi J, Nogami K (2000) D/H and 180/160 ratios of water in the crater lake at Kusatsu-Shirane volcano, Japan. J Volcanol Geotherm Res 97:329-346. https://doi.org/10.1016/S0377-0273(99)00169-9

Ohba T, Yaguchi M, Kumehara S, Terada A (2016) Volcanic activity of Mt Kusatsu-Shirane suggested by the variations in fumarolic gas composition and crater lake water chemistry. Abstracts of Japan Geoscience Union Meeting 2016 SVC45-01 (in Japanese).

Ohminato T (2006) Characteristics and source modeling of broadband seismic signals associated with the hydrothermal system at Satsuma-Iwojima volcano, Japan. J Volcanol Geotherm Res 158:467-490. https://doi.org/10. 1016/j.jvolgeores.2006.08.004

Ohwada M, Ohba T, Hirabayashi J, Nogami K, Nakamura K, Nagao K (2003) Interaction between magmatic fluid and meteoric water, inferred from $18 \mathrm{O} / 16 \mathrm{O}$ and $36 \mathrm{Ar} / \mathrm{H} 2 \mathrm{O}$ ratios of fumarolic gases at the Kusatsu Shirane volcano, Japan. Earth Planets Space 55:105-110. https://doi.org/10.1186/ BF03351737

Ossaka J, Ozawa T, Nomura T, Ossaka T, Hirabayashi J, Takaesu A, Hayashi T (1980) Variation of chemical compositions in volcanic gases and waters at Kusatsu-Shirane volcano and its activity in 1976. Bull Volcanol 43:207-216

Phillips WS, Aki K (1986) Site amplification of coda waves from local earthquakes in central California. Bull Seismo Soc Am 76(3):627-648

Rust AC, Balmforth NJ, Mandre S (2008) The feasibility of generating lowfrequency volcano seismicity by flow through a deformable channel. Geol Soc Spec Publ. https://doi.org/10.1144/SP307.4
Stix J, de Moor JM (2018) Understanding and forecasting phreatic eruptions driven by magmatic degassing. Earth Planets Space 70:83. https://doi. org/10.1186/s40623-018-0855-z

Saito K, Honda S, Miyamura J, Kokubo K, Saito M (2013) Significance of trial boring at borehole-type volcano observation station. Q J Seismol 77:111118 ((in Japanese with English abstract))

Takahashi K, Fujii I (2014) Long-term thermal activity revealed by magnetic measurements at Kusatsu-Shirane volcano, Japan. J Volcanol Geotherm Res 285:180-194. https://doi.org/10.1016/j.jvolgeores.2014.08.014

Takemura S, Furumura T, Saito T (2009) Distortion of the apparent S-wave radiation pattern in the high-frequency wavefield: Tottori-Ken Seibu, Japan earthquake of 2000. Geophys J Int 178:950-961. https://doi.org/10. 1111/.j.1365-246X.2009.04210.x

Tameguri T, Iguchi M, Nakamichi H, Yamamoto K (2016) Disaster Research of Kuchinoerabujima Eruptions in 2014-2015. Annuals of Disas Prev Res Inst 59(A) (in Japanese with English abstract).

Tanada T, Ueda H, Nagai M, Ukawa M (2017) NIED's V-net, the fundamental volcano observation network in Japan. J Disaster Res 12:926-931. https:// doi.org/https://doi.org/10.20965/jdr.2017.p0926.

Terada A, Aoyama H, Nogami K, Yamawaki T, Saito M (2011) A source model of the ground deformation observed during the volcanic tremor on 27 May 2011: An image of a volcanic fluid ascent process inferred from a tiltmeter net- work of Kusatsu-Shirane volcano. Abstracts of the Volcanological Society of Japan 2011 Fall Meeting: A3-01 (in Japanese).

Terada A, Sakamoto Y, Kanda W, Ogawa Y (2016) Mass budgets of hydrothermal water beneath hot crater lakes at Kusatsu-Shirane volcano evaluated by ground deformation and changes in thermal activities. Abstracts of Japan Geoscience Union Meeting 2016 SVC45-05.

Terada A, Hashimoto T (2017) Variety and sustainability of volcanic lakes: Response to subaqueous thermal activity predicted by a numerical model. J Geophys Res Solid Earth 122:6108-6130. https://doi.org/10. 1002/2017JB014387

Terada A (2018) Kusatsu-Shirane volcano as a site of phreatic eruptions. Jour Geol Soc Japan 124(4):251-270 ((in Japanese and English abstract))

The Joint Research Team for ash fall in Kusatsu-Shirane 2018 eruption (2018) Ash fall distribution of Jan. 23, 2018, eruption in Kusatsu-Shirane Volcano. Reports of Coordinating Committee for Prediction of Volcanic Eruption No.129. Jpn Meteorol Agency, Tokyo. https://www.data.jma.go.jp/svd/ vois/data/tokyo/STOCK/kaisetsu/CCPVE/Report/129/kaiho_129_10.pdf. Accessed 15 July 2020.

Tseng KH, Ogawa Y, Nurhasan, et al (2020) Anatomy of active volcanic edifice at the Kusatsu-Shirane volcano, Japan, by magnetotellurics: hydrothermal implications for volcanic unrests. Earth, Planets Space. https://doi.org/10. 1186/s40623-020-01283-2

Ueda H, Nagai M, Tanada T (2018) Phreatic eruptions and deformation of loto Island (Iwo-jima), Japan, triggered by deep magma injection. Earth Planets Space 70:38. https://doi.org/10.1186/s40623-018-0811-y

Ueki K, Terada A (2012) Field excursion guide to Kusatsu-Shirane volcano. Bull Volcanol Soc Japan 57:235-251 ((in Japanese))

Usu Volcano Observatory (1997) The March, 1996 Eruption of Mt. Komagatake, Hokkaido. Reports of Coordinating Committee for Prediction of Volcanic Eruption No.66. Jpn Meteorol Agency, Tokyo. http://www.data.jma.go.jp/ svd/vois/data/tokyo/STOCK/kaisetsu/CCPVE/Report/066/kaiho_066_02. pdf. Accessed 15 July 152020.

Uto K, Kurihara A, Hirabayashi I (2004) Core descriptions of seismological observation wells around Shirane cone, Kusatsu Shirane volcano. Report of 4th Joint Observation of Kusatsu-Shirane Volcano 59-68.

Voight B (1988) A method for prediction of volcanic eruptions. Nature 332:125-130. https://doi.org/10.1038/332125a0

Walsh B, Jolly AD, Procter J (2017) Calibrating the amplitude source location (ASL) method by using active seismic sources: An example from Te Maari volcano, Tongariro National Park, New Zealand. Geophys Res Lett 44:3591-3599. https://doi.org/10.1002/2017GL073000

Walsh B, Procter J, Lokmer I et al (2019) Geophysical examination of the 27 April 2016 Whakaari/White Island, New Zealand, eruption and its implications for vent physiognomies and eruptive dynamics. Earth, Planets Space 71:25. https://doi.org/10.1186/s40623-019-1003-0 
Yamamoto M, Aoyama H, Tsutsui T, Terada A, Kanada W, Ogawa W (2018) Temporary seismic observation at Kusatsu-Shirane volcano, Japan. Abstracts of Japan Geoscience Union Meeting 2018 SVC41-P10.

Yukutake Y, Honda R, Harada M et al (2017) Analyzing the continuous volcanic tremors detected during the 2015 phreatic eruption of the Hakone volcano. Earth Planets Space 69:164. https://doi.org/10.1186/ s40623-017-0751-y

Yukutake Y, Ichihara M, Honda R (2018) Infrasonic wave accompanying a crack opening during the 2015 Hakone eruption. Earth Planets Space 70:53. https://doi.org/10.1186/s40623-018-0820-x

\section{Publisher's Note}

Springer Nature remains neutral with regard to jurisdictional claims in published maps and institutional affiliations.

\section{Submit your manuscript to a SpringerOpen ${ }^{\circ}$ journal and benefit from:}

- Convenient online submission

- Rigorous peer review

- Open access: articles freely available online

- High visibility within the field

- Retaining the copyright to your article

Submit your next manuscript at $\boldsymbol{\nabla}$ springeropen.com 